\title{
In Situ Reference Datasets From the TropiSAR and AfriSAR Campaigns in Support of Upcoming Spaceborne Biomass Missions
}

\author{
Nicolas Labrière ${ }^{(\circledR)}$, Shengli Tao, Jérôme Chave, Klaus Scipal, Thuy Le Toan, Katharine Abernethy ${ }^{\circledR}$, \\ Alfonso Alonso, Nicolas Barbier, Pulchérie Bissiengou, Tânia Casal, Stuart J. Davies, Antonio Ferraz ${ }^{(\mathbb{B}}$, \\ Bruno Hérault, Gaëlle Jaouen, Kathryn J. Jeffery ${ }^{\circledR}$, David Kenfack, Lisa Korte, Simon L. Lewis, \\ Yadvinder Malhi, Hervé R. Memiaghe, John R. Poulsen, Maxime Réjou-Méchain, \\ Ludovic Villard, Grégoire Vincent, Lee J. T. White, and Sassan Saatchi
}

\begin{abstract}
Tropical forests are a key component of the global carbon cycle. Yet, there are still high uncertainties in forest carbon stock and flux estimates, notably because of their spatial and temporal variability across the tropics. Several upcoming spaceborne missions have been designed to address this gap. High-quality ground data are essential for accurate calibration/validation so that spaceborne biomass missions can reach their full potential in reducing uncertainties regarding forest carbon stocks and fluxes. The BIOMASS mission, a $\boldsymbol{P}$-band SAR satellite from the European Space Agency (ESA), aims at improving carbon stock mapping and reducing uncertainty in the carbon fluxes from deforestation, forest degradation, and regrowth. In situ activities in support of the BIOMASS mission were carried out in French Guiana and Gabon during the TropiSAR and AfriSAR campaigns. During these campaigns, airborne $\boldsymbol{P}$-band SAR, forest inventory, and lidar data were collected over six study sites. This paper describes the methods used for forest inventory and lidar data collection and analysis, and presents resulting plot estimates and aboveground biomass maps. These reference datasets along with intermediate products (e.g., canopy height models) can be accessed through ESA's Forest Observation System and the Dryad data repository and will be useful for BIOMASS but also to other spaceborne biomass missions such as GEDI, NISAR, and Tandem-L for calibration/validation purposes. During data quality control and analysis, prospects for reducing uncertainties have been identified, and this paper finishes with a series of recommendations for future tropical forest field campaigns to better serve the remote sensing community.
\end{abstract}

Index Terms-Carbon, ecology, environmental monitoring, remote sensing, surface topography, synthetic aperture radar, vegetation.

Manuscript received October 31, 2017; revised February 23, 2018 and May 16, 2018; accepted June 14, 2018. This work was supported in part by "Investissement d'Avenir" grants managed by Agence Nationale de la Recherche (CEBA, ref. ANR-10-LABX-2501; TULIP, ref. ANR-10-LABX0041; ANAEE-France, ref. ANR-11-INBS-0001), in part by the Centre National d'Etudes Spatiales (CNES), in part by the CTFS-ForestGEO, in part by the European Regional Development Fund (ERDF contract no. 2907 dated 4 November 2008), in part by the European Space Agency (ESA), in part by the IFBN project (contract 4000114425/15/NL/FF/gp), "Maboumine" (ERAMETCOMILOG), NASA Science Mission Directorate, RAINFOR funds (Moore Foundation), and Shell Gabon. (Corresponding author: Nicolas Labrière.)

N. Labrière, S. Tao, and J. Chave are with Laboratoire Evolution et Diversité Biologique (EDB) UMR 5174, 31062, Toulouse cedex 9, France (e-mail: nicolas.labriere@gmail.com; shengli.tao@univ-tlse3.fr; jerome.chave @ univ-tlse3.fr).

K. Scipal and T. Casal are with European Space Agency (ESA), Noordwijk 2201, The Netherlands (e-mail: klaus.scipal@esa.int; tania.casal@esa.int).
T. Le Toan and L. Villard are with the Centre d'Etudes Spatiales de la Biosphère (CESBIO) 31401, Toulouse cedex 9, France (e-mail: thuy. letoan@cesbio.cnes.fr; ludovic.villard@cesbio.cnes.fr).

K. Abernethy is with the Faculty of Natural Sciences, University of Stirling, Stirling FK9 4LA, U.K., and also with the Institut de Recherche en Écologie Tropicale (IRET), Centre National de la Recherche Scientifique et Technologique (CENAREST), Libreville 13354, Gabon (e-mail: k.a.abernethy@stir.ac.uk).

A. Alonso and L. Korte are with the Center for Conservation and Sustainability, Smithsonian Conservation Biology Institute, Washington, DC 20560-0705 USA (e-mail: alonsoa@si.edu; lisakorte@earthlink.net).

N. Barbier, M. Réjou-Méchain, and G. Vincent are with the Institut de Recherche pour le Développement (IRD) 34398, Montpellier cedex 5, France (e-mail: nicolas.barbier@ird.fr; maxime.rejou@gmail.com; gregoire. vincent@ird.fr).

P. Bissiengou is with the Herbier National du Gabon, Institut de Pharmacopée et de Médecine Traditionnelle (IPHAMETRA), Centre National de la Recherche Scientifique et Technologique (CENAREST), Libreville 13354, Gabon (e-mail: bissiengou_p@yahoo.fr).

S. J. Davies and D. Kenfack are with the Center for Tropical Forest Science - Forest Global Earth Observatory, Smithsonian Tropical Research Institute, Washington, DC 20560 USA (e-mail: DaviesS@si.edu; KenfackD@si.edu).

A. Ferraz and S. Saatchi are with the Jet Propulsion Laboratory, California Institute of Technology, Pasadena, CA 91109 USA (e-mail: Antonio A.Ferraz@jpl.nasa.gov; Sasan.S.Saatchi@jpl.nasa.gov).

B. Hérault is with the CIRAD, UPR Forêts et Sociétés, Campus International de Baillarguet, TA C-105/D, 34398, Montpellier cedex 5, France, and also with the Institut National Polytechnique Félix Houphouët-Boigny (INP-HB), Yamoussoukro 1093, Ivory Coast (e-mail: Bruno.Herault@cirad.fr).

G. Jaouen is with the UMR EcoFoG, Campus agronomique, 97379 Kourou cedex, France (e-mail: Gaelle.Jaouen@ecofog.gf).

K. J. Jeffery and L. J. T. White are with the Faculty of Natural Sciences, University of Stirling, Stirling FK9 4LA, U.K., and also with the Institut de Recherche en Écologie Tropicale (IRET), Centre National de la Recherche Scientifique et Technologique (CENAREST), Libreville 13354, Gabon, and also with the Agence Nationale des Parcs Nationaux, Libreville 20379, Gabon (e-mail: kjeffery@parcsgabon.ga; 1white@parcsgabon.ga).

S. L. Lewis is with the Department of Geography, University College London, London WC1E 6BT, U.K., and also with the School of Geography, University of Leeds, Leeds LS2 9JT, U.K. (e-mail: S.L.Lewis@leeds.ac.uk).

Y. Malhi is with the Environmental Change Institute, School of Geography and the Environment, University of Oxford, Oxford OX1 3QY, U.K. (e-mail: Yadvinder.malhi@ouce.ox.ac.uk).

H. R. Memiaghe is with the Institut de Recherche en Écologie Tropicale (IRET), Centre National de la Recherche Scientifique et Technologique (CENAREST), Libreville 13354, Gabon (e-mail: memiagheh@ hotmail.com).

J. R. Poulsen is with the Nicholas School of the Environment, Duke University, Durham, NC 27708 USA (e-mail: john.poulsen@ duke.edu).

Color versions of one or more of the figures in this paper are available online at http://ieeexplore.ieee.org.

Digital Object Identifier 10.1109/JSTARS.2018.2851606 


\section{INTRODUCTION}

T ROPICAL forests cover less than $10 \%$ of the surface of the earth but harbor a disproportionately high fraction of global terrestrial biodiversity [1], [2] and provide a wide range of ecosystem services [3], [4]. Stocking about a quarter of total terrestrial carbon and contributing up to a third of net primary production, tropical forests are a key component of the global carbon cycle [5]. Their contribution to climate change mitigation strategies such as REDD+ (United Nations initiative aimed at "Reducing Emissions from Deforestation and forest Degradation" through financial incentives) has come under close scrutiny [6], [7]. Yet, these strategies critically rely on accurate monitoring of carbon (C) stocks. There are still high uncertainties in large-scale estimates of both carbon stocks and fluxes, notably because of their spatial and temporal variability across the tropics [8], [9]. Several pantropical maps of forest aboveground biomass (AGB, in $\mathrm{Mg} \mathrm{ha}{ }^{-1}$ ) are available [10]-[12], but their accuracy has been questioned [12]-[14]. It is also fundamental to understand the tropical forest carbon cycle over the short and longer term (e.g., decadal versus centennial time scale). Indeed, while mature tropical forests are thought to be a carbon sink [15], [16], extreme climatic events such as droughts could potentially induce significant carbon sources [17], even though the effect would be smoothed in time because of the decay rate of dead wood [18].

Several upcoming spaceborne missions have been designed to address this challenge. Among them, the BIOMASS mission, an Earth Explorer mission from the European Space Agency (ESA), has been specifically designed to improve forest carbon stock mapping and reduce uncertainty in the carbon fluxes due to deforestation, forest degradation, and regrowth [19]. The satellite payload is composed of a $P$-band polarimetric SAR (center frequency of $435 \mathrm{MHz}$ ) that will be used to produce maps of canopy height and aboveground biomass (AGB) at 200-m resolution and deforestation at 50-m resolution twice a year during the five-year expected lifetime of this mission [20]. Launch is planned for 2021. Complementary to BIOMASS, NASA will launch GEDI, a lidar instrument onboard the ISS in 2018-2019. NASA is also collaborating with ISRO to launch NISAR a dualwavelength $L$-band and $S$-band SAR aimed at retrieving biomass from dry forests and woodlands. Finally, DLR is currently developing Tandem-L, a proposal for an interferometric and polarimetric SAR mission with two satellites operating in $L$-band [21]. Provided funding approval, the satellites could be launched in 2023. Together these missions are poised to revolutionize the quantification of biomass stocks and fluxes at a global scale.

Preliminary activities in support of the BIOMASS mission include the building of inversion algorithms for AGB and canopy height retrieval from the backscatter signal. The algorithm development is based on experimental data acquired during campaigns that provide airborne SAR data and in situ forest data. To that purpose, airborne SAR campaigns have been conducted in French Guiana during the 2009 TropiSAR campaign [22], and more recently in Gabon during the 2015-2016 AfriSAR campaign [23]. These SAR acquisitions were conducted by ONERA, NASA, and DLR, over areas where forest inventory data and small-footprint lidar were also collected.

A standardized analysis of both forest inventory and lidar datasets was commissioned by ESA to provide the re-

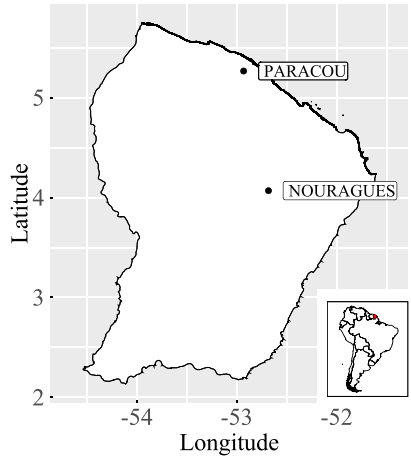

(a)

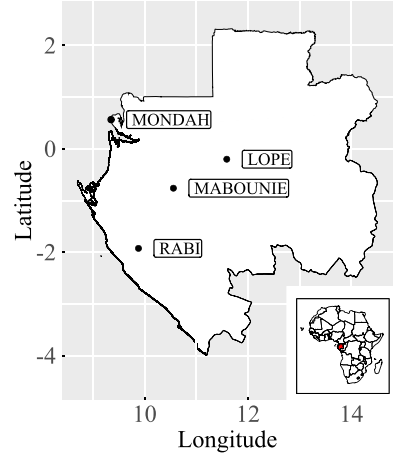

(b)
Fig. 1. Location of the selected study sites. (a) For the TropiSAR campaign in French Guiana $(n=2)$. (b) For the AfriSAR campaign in Gabon $(n=4)$.

search community with a reference ground dataset of AGB estimates at two spatial resolutions over the in situ plots $(100 \mathrm{~m}$ $\times 100 \mathrm{~m}$ and $50 \mathrm{~m} \times 50 \mathrm{~m}$, i.e., 1-ha and 0.25-ha resolution, respectively), and lidar-derived AGB maps (originally produced at 0.25 -ha resolution and coarsened to 1-ha and 4ha resolution through aggregation) over each study site. Digital terrain models (DTM) and canopy height models built at $1-\mathrm{m}$ resolution are also made available - upon request to the study site PIs-along with georeferenced polygons for all the 1-ha and 0.25-ha calibration points. The purpose of this paper is to document these forest datasets and outline intersite comparisons regarding the biomass and forest structure. The reference datasets are archived in ESA's Forest Observation System (http://forest-observation-system.net/) and the Dryad data repository (https://doi.org/10.5061/dryad.467hp97) and will be useful to all spaceborne biomass missions for calibration/validation purposes (e.g., through resampling highresolution products to meet mission-specific spatial resolution). This paper (1) briefly describes the study sites selected for the two campaigns, (2) provides details about data collection and analysis procedures, (3) presents and compares field-based and lidar-derived vegetation structure characteristics at the plot scale (e.g., stem density, basal area) and at the landscape scale (e.g., top-of-canopy height, biomass) across the study sites, and (4) discusses key points for future ground data campaigns for the remote sensing community.

\section{SITE DESCRIPTION}

The 2009 TropiSAR campaign took place at two study sites in French Guiana, and the 2015-2016 AfriSAR campaign at four areas in Gabon. These sites were selected in well-studied areas encompassing various vegetation types and covering a wide range of vegetation structure characteristics, topography, and disturbance regimes (see Fig. 1 and Fig. 6 in Appendix A).

\section{A. TropiSAR Campaign}

1) Nouragues: The Nouragues study site $\left(4.06^{\circ} \mathrm{N}, 52.68^{\circ}\right.$ W) is located ca. $100 \mathrm{~km}$ south of Cayenne, French Guiana. The terrain is gently hilly, with an altitude ranging between 26 and $280 \mathrm{~m}$ above sea level (asl) except in the northern part of the area where a granitic outcrop (inselberg) reaches $430 \mathrm{~m}$ asl. Mean annual rainfall is ca. $2860 \mathrm{~mm} \mathrm{yr}^{-1}$ (1992-2012 average), 
with a two-month dry season from September to November and a shorter one in March [24]. Mean annual temperature is $26^{\circ} \mathrm{C}$. The clayey to sandy-clay soils found in the area have developed from metamorphic or granitic parental material. Beside high-canopy old-growth forest, a range of lower-canopy forest formations are observed in the area, including periodically flooded forest dominated with Euterpe palm, low forest, liana forest, and bamboo thickets. There are typically about 145 tree species (with diameter at breast height $\geq 10 \mathrm{~cm}$ ) per ha. The area is under total protection since 1996 and there is no evidence of major disturbances during the last 100 years [24], [25].

2) Paracou: The Paracou study site $\left(5.27^{\circ} \mathrm{N}, 52.93^{\circ} \mathrm{W}\right)$ is located ca. $75 \mathrm{~km}$ West of Cayenne (https://paracou.cirad.fr). The altitude ranges between 5 and $45 \mathrm{~m}$ asl over an undulating terrain where clayey-sandy soils are developed from schists and sandstones. Mean annual rainfall is ca. $3040 \mathrm{~mm} \mathrm{yr}^{-1}$ (1979-2001 period) and mean temperature is $26^{\circ} \mathrm{C}$ [26]. Mean tree species richness (ca. 140 per ha) is comparable to that in Nouragues. The research station was established in 1984 in an area of disturbance-free moist evergreen rain forest to initiate an experimental disturbance program (see [27] for details about the different treatments). The main setup includes 16 permanent plots, and another plot clear-cut in 1976 (called Arbocel) was included into the setup in 1992.

\section{B. AfriSAR Campaign}

1) Lopé: The Lopé study site $\left(0.20^{\circ} \mathrm{S}, 11.59^{\circ} \mathrm{E}\right)$ is located near the geographical center of Gabon, ca. $250 \mathrm{~km}$ East of Libreville. Topography is gently hilly, with an altitude ranging from 200 to $600 \mathrm{~m}$ asl. Mean annual rainfall is ca. $1440 \mathrm{~mm}$ $\mathrm{yr}^{-1}$ (1984-2016 period), with a major dry season from midJune to mid-September. Temperature ranges from $20-23^{\circ} \mathrm{C}$ and $26-33{ }^{\circ} \mathrm{C}$ for mean monthly minima and maxima, respectively. Sandy clay to sandy clay loam soils dominate the area, originating mostly from metamorphic rocks [28]. Vegetation over the Lopé study site is a forest-savanna mosaic with different forest types such as Aucoumea-dominated forests and Marantaceae forests co-occurring in the area [29]. There are on an average 35 tree species richness per ha, with high disparities between savanna and forest as well as between forest types. Lopé national park is a UNESCO World Heritage site since 2007, recognition of its unique biological and archaeological values.

2) Mabounié: The Mabounié study site $\left(0.76^{\circ} \mathrm{S}, 10.56^{\circ} \mathrm{E}\right)$ is located ca. $180 \mathrm{~km}$ Southeast of Libreville. Altitude ranges between 25 and $230 \mathrm{~m}$ asl over an area where Rubiaceae, Fabaceae (Caesalpinioideae and Faboideae), and Euphorbiaceae are dominant families. Mean temperature is $26^{\circ} \mathrm{C}$ and mean annual rainfall is ca. $2030 \mathrm{~mm}$, with dry and wet seasons occurring between June and September and October and May, respectively (http://worldclim.org/version2). Sandy-clayey soils developed from gneiss and carbonatite. There are typically about 55 tree species per ha. The landscape is mostly forested (of which swamp and temporarily flooded forests constitute a large proportion) but shows evidence of degradation locally (e.g., road building). Part of the study site underwent selective logging starting in the 1960s. While mining exploration has been ongoing on-site for decades, a mining project called
"Maboumine" was initiated in 2005 following the discovery of a polymetallic deposit rich in niobium, tantalum, and rare earths.

3) Mondah: The Mondah study site $\left(0.57^{\circ} \mathrm{N}, 9.35^{\circ} \mathrm{E}\right)$ is located ca. $25 \mathrm{~km}$ Northwest of Libreville toward Cap Esterias. Altitude seldom exceeds $50 \mathrm{~m}$ asl in this coastal area where mean temperature is $25^{\circ} \mathrm{C}$ and mean annual rainfall falls within the range $3000-3500 \mathrm{~mm}$, with a dry season occurring in June-September [30]. The sandy-clayey soils in the area developed from shales and slates. Different vegetation types occur in this forested area, including Aucoumea-dominated forests and mixed forests [31]. Some zones of the Mondah study area have undergone significant disturbance (area of highest rate of deforestation across Gabon sensu Hansen et al. 2013; see [32]), but other patches remain protected [33]. Mean tree species richness is similar to that in Lopé, with high variations from one plot to the other depending on disturbance level.

4) Rabi: The Rabi study site $\left(1.92^{\circ} \mathrm{S}, 9.88^{\circ} \mathrm{E}\right)$ is located ca. $260 \mathrm{~km}$ South of Libreville. Altitude ranges from 30 to 80 $\mathrm{m}$ asl over the study area. Mean annual rainfall is ca. $2300 \mathrm{~mm}$ $\mathrm{yr}^{-1}$ with a rainfall pattern similar to that of Mabounié. Mean annual temperature lies between 24 and $28^{\circ} \mathrm{C}$. Soils are mostly sandy clay to clay sand and developed from clastic sedimentary rocks. Vegetation mostly consists in lowland tropical rain forest with Fabaceae, Euphorbiaceae, and Olacaceae among the most abundant families. There are typically about 85 tree species per ha. The study site is located within the "Rabi Oil Concession", an onshore oil-drilling site that has been operational since 1985 . Prior to this, the forest underwent selective logging [34]. While drilling activity is evident from the lidar imagery over the concession, some of the land has been set aside for preservation.

\section{Data Collection And Analysis Procedure}

Forest inventories were performed and lidar datasets acquired at different times over the 2008-2016 period. When multiple field surveys were available for a permanent plot, we chose the ones closest to the date of the corresponding lidar data acquisitions (see Table I). The absolute time difference between the forest inventory and lidar data acquisition ranged from zero to 5 years.

Because both types of datasets were obtained from multiple sources, they were carefully checked and harmonized before analysis (see Sections III-A and III-B for examples). The main steps of data collection and analysis are detailed below (see Fig. 2).

\section{A. Forest Inventory Datasets}

In all permanent plots, tree diameter at breast height $(\mathrm{DBH}$, a standard forestry measurement) was measured at $1.30 \mathrm{~m}$ from the ground wherever possible (and above the top of buttresses or above/below deformities wherever required). Tree identification and tree coordinates were available for most of the cases. Tree height measurements, acquired using a laser rangefinder, were usually only available for a subset of trees per plot (or subset of plots) aimed at spanning DBH range at each site. Tree height measurements were not systematically done alongside $\mathrm{DBH}$ inventory campaigns, potentially resulting in a time lag up to 6 years (extreme-case scenario in Rabi where DBH and tree 
TABLE I

GENERAL CHARACTERISTICS OF FOREST INVENTORY AND LIDAR DATASETS

\begin{tabular}{|c|c|c|c|c|c|c|c|c|c|}
\hline \multirow[b]{2}{*}{ Campaign } & \multirow[b]{2}{*}{ Site } & \multicolumn{4}{|c|}{ Forest inventory dataset } & \multicolumn{4}{|c|}{ Lidar dataset } \\
\hline & & $\begin{array}{l}\text { Year of } \\
\text { forest } \\
\text { inventory }\end{array}$ & $\begin{array}{l}\text { Number of } \\
\text { permanent } \\
\text { plots }\end{array}$ & $\begin{array}{l}\text { Total } \\
\text { plot } \\
\text { area } \\
\text { (ha) }\end{array}$ & $\begin{array}{l}\text { Number of } \\
\text { trees with } \\
\text { DBH } \geq 10 \\
\mathrm{~cm} \text { (number } \\
\text { of species) }\end{array}$ & $\begin{array}{l}\text { Year of } \\
\text { lidar data } \\
\text { acquisition }\end{array}$ & $\begin{array}{l}\text { Lidar system and } \\
\text { acquisition } \\
\text { characteristics } \\
\text { (device - carrier - } \\
\text { wavelength) }\end{array}$ & $\begin{array}{l}\text { ROI }^{\text {a }} \\
\text { covered } \\
\text { by lidar } \\
\text { (ha) }\end{array}$ & $\begin{array}{l}\text { Average lidar } \\
\text { point density } \\
\left(\mathrm{m}^{-2}\right)\end{array}$ \\
\hline \multirow[t]{2}{*}{$\begin{array}{l}\text { TropiSAR } \\
(2009)\end{array}$} & Nouragues & $\begin{array}{l}2010 \text { and } \\
2012\end{array}$ & 11 & 34 & $17350(823)$ & 2012 & $\begin{array}{l}\text { RIEGL LMS-Q560 } \\
- \text { aircraft }-1.5 \mu \mathrm{m}\end{array}$ & 2400 & $19.9(0.3)^{b}$ \\
\hline & $\begin{array}{l}\text { Paracou } \\
\text { (incl. Arbocel) }\end{array}$ & 2009 & 17 & 125 & $79167(753)$ & 2009 & $\begin{array}{l}\text { RIEGL LMS- } 280 \mathrm{i}- \\
\text { helicopter }-0.9 \mu \mathrm{m}\end{array}$ & 1100 & $5.7(0.1)$ \\
\hline \multirow[t]{4}{*}{$\begin{array}{l}\text { AfriSAR } \\
(2015-16)\end{array}$} & Lopé & $2016^{c}$ & 14 & 12.5 & $3710(141)$ & 2015 & $\begin{array}{l}\text { RIEGL VQ-480i-- } \\
\text { helicopter }-1.5 \mu \mathrm{m}\end{array}$ & 5400 & $2.4(0.1)$ \\
\hline & Mabounié & 2012 & 12 & 12 & $4424(196)$ & 2007 & $\begin{array}{l}\text { RIEGL LMS-Q560 } \\
\text { - aircraft }-1.5 \mu \mathrm{m}\end{array}$ & 18000 & $4.3(0.1)$ \\
\hline & Mondah & $2016^{c}$ & 19 & 19 & $5687(225)$ & 2011 & $\begin{array}{l}\text { RIEGL LMS-Q560 } \\
- \text { aircraft }-1.5 \mu \mathrm{m} \\
\end{array}$ & 9800 & $30.5(2.3)$ \\
\hline & Rabi & $\begin{array}{l}2010 \text { to } \\
2012\end{array}$ & 1 & 25 & $11601(234)$ & 2015 & $\begin{array}{l}\text { RIEGL VQ-480i- } \\
\text { helicopter }-1.5 \mu \mathrm{m}\end{array}$ & 900 & $2.5(0.05)$ \\
\hline
\end{tabular}

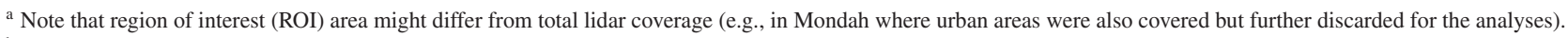

b Average lidar point density for ground points shown in brackets.

${ }^{\mathrm{c}}$ Data from plots set up within the lidar coverage at the study site prior to the main field campaign—data curated by ForestPlots.net—were also included in the analysis.

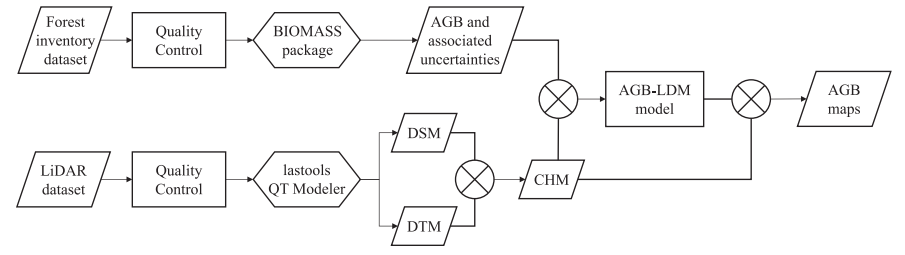

$\square$ Input/Output $\square$ Process/Model $\longrightarrow$ R package/Software $\otimes_{\text {AND symbol }}$

Fig. 2. Workflow of the data analysis procedure. Abbreviations: AGB aboveground biomass; CHM canopy height model; DSM digital surface model; DTM digital terrain model; LDM lidar-derived metrics; QT Modeler Quick Terrain Modeler.

height were measured in 2010-2012 and in 2017, respectively) but usually $\leq 1$ year between the two sets of information. The raw tree-by-tree data were checked and corrected if necessary. Frequent errors concerned:

1) tree identification (e.g., when original names were misspelled or vernacular ones used, precluding matching with a wood density database);

2) invalid relative tree coordinates (either with respect to plot dimensions or subplot location when coordinates were given at the plot scale);

3) DBH values with misplaced or missing comma, resulting in trees having DBH below minimum cutoff DBH at the corresponding site, or trees with DBH far too high compared to their species range (e.g., $244 \mathrm{~cm}$ for a specimen of Sacoglottis gabonensis (Baill.) Urb., confirmed to be $24.4 \mathrm{~cm}$ after field spreadsheet check).

When vernacular names could not be converted to scientific names (T. Stévart, pers. comm.), trees were considered unidentified. Plot description was harmonized across all sites (e.g., tree relative coordinates were consistently standardized to set the southwestern-most plot corner as relative referential origin for each plot). Because minimum DBH varied from one site to the other, only trees with $\mathrm{DBH} \geq 10 \mathrm{~cm}$ were included in the analysis for the sake of consistency. Likewise, lianas were discarded from the few datasets where they were avail- able (but note that their biomass can represent up to 3\% of that of trees with $\mathrm{DBH} \geq 10 \mathrm{~cm}$; pers. obs. from the Lopé dataset).

Aboveground biomass estimates (AGB, in megagram of dry biomass per hectare, $\mathrm{Mg} \mathrm{ha}^{-1}$ ) based on plot data were produced at 1-ha and 0.25-ha (0.16-ha in case relative tree coordinates were missing) resolutions using the R BIOMASS package [35]. This package uses a Monte Carlo procedure to propagate the errors associated with diameter measurement, wood density assignment, tree height estimation, and the choice of the biomass allometric equation ("AGBmonteCarlo" function with the following error-related inputs: Dpropag = "chave2004" for diameter, and errWD and errH derived from "getWoodDensity" and "retrieveH" functions for wood density and tree height, respectively). Using field tree height measurements, we built Michaelis-Menten models [36] for each site (henceforth referred to as local H:D relationships) to locally predict tree height based on trunk DBH. A separate savanna-species H:D relationship was developed from height measurements of individuals belonging to either Crossopteryx febrifuga or Sarcocephalus latifolius (only found at Lopé).

Initially, AGB was estimated at the tree level from the measured DBH, the tree height information (either explicitly or implicitly), the wood density information (derived from the species identification of the tree; see [37] and [38]) and a biomass allometric equation also available from the R BIOMASS package [35]. Because palms can be locally abundant in the Neotropics, their contribution to overall AGB was considered for the TropiSAR sites using a family-level allometry developed for Amazonian palms [39]. This includes palms in genera Euterpe, Oenocarpus, Mauritia, and Astrocaryum. Second, AGB was obtained at a stand level by summing that of all the trees (and palms for the TropiSAR sites; note that uncertainties were not propagated for palms but that their biomass exceeded 5\% of that of trees in less than $1 \%$ of the cases) present in the stand. Overall, three AGB estimates are provided: 1) "agb_fph" using the allometric (4) in Chave et al. [40] with the variables wood density, DBH, and height derived from Feldpausch et al. [41] H:D relationship for Central Africa (AfriSAR sites) 
or the Guiana Shield (TropiSAR sites), 2) "agb_chv" using (7) in Chave et al. with the variables wood density, $\mathrm{DBH}$, and height implicitly taken into consideration through the use of bioclimatic predictor E, and 3) "agb_loc" using (4) in Chave et $a l$. with the variables wood density, DBH, and height derived from local H:D relationships. Further details about local tree $\mathrm{H}: \mathrm{D}$ relationships and tree/palm allometric equations for AGB estimation can be found in Appendix B.

\section{B. Lidar Datasets}

Lidar data were acquired at all sites. For some of them (e.g., Mondah and Mabounié), ground point classification was absent in the .las files. In this case, ground points were first extracted using the lastools software ("lasground_new" function, step 25, bulge 30) before visual inspection of the newly classified point cloud and manual refinement if necessary (i.e., removal of individual points classified as "ground" in case they were found lying well above or below the other ones). Average point density (either for all or ground points) varied by one order of magnitude across sites (see Table I). Large intra-site variation in point density was observed and some small regions had no lidar returns (e.g., at Mabounié site). Yet, in order to facilitate inter-site comparison, DTM and digital surface models (DSM; free of pits and spikes using the Quick Terrain Modeler software with "Hole Fill" set as "Adaptive Triangulation") were built at 1-m resolution for each site by interpolating ground and highest points on a 1-m grid, respectively. The canopy height model (CHM) was then obtained by subtracting the DTM from the DSM (see Fig. 2).

\section{Refining Permanent Plot Georeferencing}

For some plots, GPS location was generally obtained by handheld GPS, at an accuracy of 5-10 m. To improve georeferencing, we compared the GPS locations of emergent trees (the 4\%largest trees in the plot) inferred from ground positioning to that deduced from the lidar scene (see also [24]). We shifted the tree GPS coordinates to best-match the lidar-derived CHM, resulting in horizontal shifts typically of less than $10 \mathrm{~m}$. At Mabounié, relative tree coordinates were missing so it was not possible to apply this procedure.

\section{AGB-LDM Model}

Several small-footprint lidar-derived metrics (LDM) have proven successful in predicting AGB in tropical forests at the landscape scale. These LDM include mean top-of-canopy height (TCH; see [42] and [43]) or median height of $\mathrm{CHM}\left(\mathrm{H}_{50}\right.$; see [24]). The tested models generally related AGB to a power law of the LDM. Ordinary least squares regressions on log-log transformed data were performed for the simplest of such power-law models as follows:

$$
\ln (\mathrm{AGB})=a+b \times \ln (\mathrm{LDM})+\varepsilon
$$

where $\varepsilon$ is an error term assumed to be normally distributed with zero mean. Back-transformation to the original scale and multiplication by a correction factor to account for a known bias in an error structure (i.e., larger errors associated with large values) [44] led to the following model for stand-scale AGB predictions:

$$
\widehat{\mathrm{AGB}}=\exp \left(a+\sigma^{2} / 2\right) \times \mathrm{LDM}^{b}
$$

where $\sigma$ is the estimated standard deviation of the residuals of the $\log -\log$ regression and $\exp \left(\sigma^{2} / 2\right)$ the aforementioned correction factor. An "all-sites" model as well as site-specific ones were built using calibration points at 1 -ha and 0.25 -ha resolution, independently. A leave-one-site-out (LOSO) procedure, where models are calibrated without, and validated with, all the site-specific calibration points, was used to evaluate model transferability for the "all-sites" model.

\section{E. Statistical Analysis}

All statistical analyses were done using R 3.4.0 [45]. We performed pairwise regressions to investigate the correlation among AGB estimates inferred from the three allometric equations. We tested for differences (at $p<0.01$ ) in the field-based and lidar-derived vegetation structure characteristics depending on the study site using analysis of variance followed by Tukey's honest significant difference (HSD). Root-mean-square error (RMSE), coefficient of correlation $\left(R^{2}\right)$ and bias were calculated on back-transformed values for LDM (TCH versus $\mathrm{H}_{50}$ ) as well as model (site-specific versus "all-sites") selection, and those with the lowest RMSE and bias—and highest $R^{2}$ —were selected to produce AGB maps at the landscape scale.

\section{RESULTS}

\section{A. At the Plot Scale}

1) Allometries for AGB Estimation: We found that ground AGB estimates, as inferred from the three allometric equations, were highly correlated with each other $\left(R^{2}>0.99\right)$. The Feldpausch-derived allometry consistently led to higher mean AGB estimates compared to the two other allometries. The 95\% credibility intervals often overlapped for AGB estimates from one allometry to the other (see Fig. 7 in Appendix A). AGB estimates where tree height was inferred from locally derived H:D relationships were selected for all the subsequent analyses [40]. Thus, "agb_loc" will be the only field-based AGB estimates considered hereinafter (although the data product contains all the values).

2) Vegetation Structure Characteristics: The degree of botanical determination varied greatly across sites, ranging 26-77\% and $69-97 \%$ for stem identification to species and genus, respectively (see Table II). At each site, the two LDM of stand canopy height $\left(\mathrm{TCH}\right.$ and $\mathrm{H}_{50}$ ) had similar mean values though variability was always higher for the latter. AGB was significantly higher at Nouragues, due to significantly higher canopy height and BA (but not WD) compared to other study sites. AGB was significantly lower at Mondah, where canopy height, BA, and WD were all significantly lower compared to other study sites. Lopé and Mondah consistently showed highest variability across field-based and lidar-derived vegetation structure characteristics. This reflects the fact that sampling at those sites was specifically designed to encompass a broader range of natural and human-disturbed vegetation types-some of them nonforest - compared to other sites (e.g., savanna at Lopé, and derived woodland sensu Putz and Redford [46] at Mondah). 
TABLE II

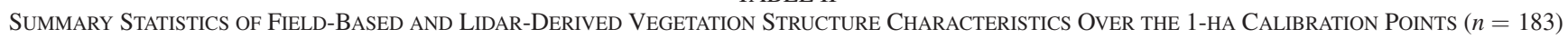

\begin{tabular}{|c|c|c|c|c|c|c|c|c|}
\hline \multirow[t]{2}{*}{ Site } & \multirow{2}{*}{$\begin{array}{l}\text { Number of 1-ha } \\
\text { calibration } \\
\text { points }\end{array}$} & \multirow{2}{*}{$\begin{array}{l}\text { Percent stem } \\
\text { identified to } \\
\text { species (genus) }\end{array}$} & \multicolumn{6}{|l|}{ Mean (SD) } \\
\hline & & & $\begin{array}{l}\text { Stem density } \\
\left(\mathrm{ha}^{-1}\right)\end{array}$ & $\begin{array}{l}\text { TCH } \\
(\mathrm{m})\end{array}$ & $\begin{array}{l}\mathrm{H}_{50} \\
(\mathrm{~m})\end{array}$ & $\begin{array}{l}\text { BA } \\
\left(\mathrm{m}^{2} \mathrm{ha}^{-1}\right)\end{array}$ & $\begin{array}{l}\text { WD } \\
\left(\mathrm{g} \mathrm{cm}^{-3}\right)\end{array}$ & $\begin{array}{l}\text { AGB } \\
\left(\mathrm{Mg} \mathrm{ha}^{-1}\right)\end{array}$ \\
\hline NOURAGUES & 33 & $51(85)$ & $\begin{array}{l}499^{a} \\
(38)\end{array}$ & $\begin{array}{l}31.5^{\mathrm{a}} \\
(3.3)\end{array}$ & $\begin{array}{l}31.8^{\mathrm{a}} \\
(4.0)\end{array}$ & $\begin{array}{l}31.6^{\mathrm{a}} \\
(5.1)\end{array}$ & $\begin{array}{l}0.665^{a b c} \\
(0.034)\end{array}$ & $\begin{array}{l}404.6^{\mathrm{a}} \\
(83.2)\end{array}$ \\
\hline $\begin{array}{l}\text { PARACOU } \\
\text { (incl. Arbocel) }\end{array}$ & 89 & 77 (97) & $\begin{array}{l}627^{b} \\
(103)\end{array}$ & $\begin{array}{l}26.8^{\mathrm{b}} \\
(3.6)\end{array}$ & $\begin{array}{l}27.2^{b} \\
(3.9)\end{array}$ & $\begin{array}{l}28.9^{\mathrm{ab}} \\
(3.8)\end{array}$ & $\begin{array}{l}0.688^{\mathrm{a}} \\
(0.035)\end{array}$ & $\begin{array}{l}345.3^{\mathrm{ab}} \\
(72.7)\end{array}$ \\
\hline LOPE & 10 & $61(96)$ & $\begin{array}{l}303^{c} \\
(158)\end{array}$ & $\begin{array}{l}25.6^{\mathrm{ab}} \\
(13.5)\end{array}$ & $\begin{array}{l}25.8^{\mathrm{ab}} \\
(14.0)\end{array}$ & $\begin{array}{l}25.4^{\mathrm{ab}} \\
(13.1)\end{array}$ & $\begin{array}{l}0.614^{\mathrm{b}} \\
(0.090)\end{array}$ & $\begin{array}{l}298 \text { abc } \\
(171.6)\end{array}$ \\
\hline MABOUNIE & 12 & $44(77)$ & $\begin{array}{l}369^{\mathrm{cd}} \\
(68)\end{array}$ & $\begin{array}{l}28.1^{\mathrm{ab}} \\
(6.1)^{2}\end{array}$ & $\begin{array}{l}28.4^{a b} \\
(7.0)\end{array}$ & $\begin{array}{l}26.1^{\mathrm{ab}} \\
(4.4)\end{array}$ & $\begin{array}{l}0.694^{\mathrm{ac}} \\
(0.027)\end{array}$ & $\begin{array}{l}349.6^{\mathrm{ab}} \\
(97.2)\end{array}$ \\
\hline MONDAH & 14 & $36(87)$ & $\begin{array}{l}309^{c} \\
(162)\end{array}$ & $\begin{array}{l}15.5^{\mathrm{c}} \\
(11.9)\end{array}$ & $\begin{array}{l}15.1^{\mathrm{c}} \\
(13.0)\end{array}$ & $\begin{array}{l}16.8^{\mathrm{c}} \\
(13.6)\end{array}$ & $\begin{array}{l}0.528^{\mathrm{d}} \\
(0.074)\end{array}$ & $\begin{array}{l}172.1^{\mathrm{c}} \\
(162.6)\end{array}$ \\
\hline RABI & 25 & $26(69)$ & $\begin{array}{l}464^{\text {ad }} \\
(33)\end{array}$ & $\begin{array}{l}24.8^{b} \\
(2.9)\end{array}$ & $\begin{array}{l}24.8^{\mathrm{b}} \\
(3.4)\end{array}$ & $\begin{array}{l}25.6^{\mathrm{b}} \\
(3.3)\end{array}$ & $\begin{array}{l}0.650^{\mathrm{bc}} \\
(0.025)\end{array}$ & $\begin{array}{l}314.6^{\mathrm{b}} \\
(63.6)\end{array}$ \\
\hline
\end{tabular}

Mean values with the same letter are not significantly different (Tukey's HSD test, $p<0.01$ ). Summary statistics on AGB are based on "agb_loc" estimates. Abbreviations: BA basal area; $\mathrm{H}_{50}$ median height of the canopy height model; TCH mean top-of-canopy height; WD basal area-weighted wood density.

TABLE III

COMPARISON OF MOdel PERformances FOR StAND-SCALE AGB PREDiction

\begin{tabular}{|c|c|c|c|c|c|c|c|c|c|c|}
\hline \multirow[b]{2}{*}{ Resolution } & \multirow[b]{2}{*}{ Site } & \multirow[b]{2}{*}{$\begin{array}{l}\text { Number of } \\
\text { calibration } \\
\text { points }\end{array}$} & \multicolumn{4}{|l|}{$\mathrm{TCH}$} & \multicolumn{4}{|l|}{$\mathrm{H}_{50}$} \\
\hline & & & $\begin{array}{l}\text { RMSE } \\
\left(\mathrm{Mg} \mathrm{ha}^{-1}\right)\end{array}$ & $\begin{array}{l}\text { bias } \\
(\%)\end{array}$ & $\begin{array}{l}\text { LOSO RMSE } \\
\left(\mathrm{Mg} \mathrm{ha}^{-1}\right)\end{array}$ & $\begin{array}{l}\text { LOSO } \\
\text { bias } \\
(\%)\end{array}$ & $\begin{array}{l}\text { RMSE } \\
\left(\mathrm{Mg} \mathrm{ha}^{-1}\right)\end{array}$ & $\begin{array}{l}\text { bias } \\
(\%)\end{array}$ & $\begin{array}{l}\text { LOSO RMSE } \\
\left(\mathrm{Mg} \mathrm{ha}^{-1}\right)\end{array}$ & $\begin{array}{l}\text { LOSO } \\
\text { bias } \\
(\%)\end{array}$ \\
\hline \multirow[t]{7}{*}{$1 \mathrm{ha}$} & ALL & 183 & $51.7(0.79)$ & 1.7 & $\begin{array}{llll}- & & & \end{array}$ & - & $47.5(0.81)$ & 2.1 & 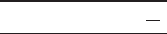 & - \\
\hline & NOURAGUES & 33 & $60.1(0.50)$ & 0.1 & $60.2(0.50)$ & 1.2 & $58.3(0.53)$ & 0.1 & $61.3(0.53)$ & -4.2 \\
\hline & PARACOU & 89 & $41.1(0.65)$ & 0.3 & $40.7(0.65)$ & 0.4 & $42.0(0.64)$ & 0.4 & $42.6(0.65)$ & 4.8 \\
\hline & LOPE & 10 & $102.7(0.74)$ & 17.2 & $113.2(0.71)$ & 18.2 & $190.5(0.78)$ & 50.9 & $88.2(0.76)$ & 11.1 \\
\hline & MABOUNIE & 12 & $36.8(0.83)$ & 0.1 & $49.7(0.82)$ & 5.3 & $41.4(0.78)$ & 0.2 & $45.3(0.78)$ & 4.2 \\
\hline & MONDAH & 14 & $130.6(0.83)$ & 18.1 & $56.6(0.89)$ & 2.7 & $51.2(0.93)$ & 9.4 & $40.2(0.94)$ & 9.6 \\
\hline & RABI & 25 & $31.4(0.73)$ & -0.1 & $31.1(0.73)$ & 1.2 & $32.0(0.72)$ & -0.1 & $35.9(0.72)$ & 5.4 \\
\hline \multirow[t]{7}{*}{$0.25 \mathrm{ha}$} & ALL & 894 & $82.0(0.60)$ & 2.1 & - & $\begin{array}{c}{ }_{-} \\
-\end{array}$ & $77.0(0.62)$ & 1.9 & - & - \\
\hline & NOURAGUES & 131 & $90.7(0.45)$ & 0.1 & $91.1(0.45)$ & 1.6 & $92.2(0.43)$ & 0.1 & $93.5(0.43)$ & -3.4 \\
\hline & PARACOU & 500 & $55.8(0.56)$ & 0.3 & $55.7(0.56)$ & -1.8 & $57.2(0.54)$ & 0.3 & $56.2(0.55)$ & 2.0 \\
\hline & LOPE & 45 & $120.0(0.60)$ & 7.0 & $143.3(0.58)$ & 20.0 & $130.4(0.62)$ & 19.7 & $128.5(0.61)$ & 16.1 \\
\hline & MABOUNIE & 48 & $127.7(0.27)$ & -0.1 & $148.5(0.25)$ & 7.0 & $126.4(0.29)$ & -0.1 & $133.8(0.28)$ & 5.8 \\
\hline & MONDAH & 70 & $139.5(0.78)$ & 21.6 & $105.0(0.81)$ & 17.5 & $96.8(0.83)$ & 16.2 & $85.6(0.84)$ & 15.9 \\
\hline & RABI & 100 & $70.7(0.46)$ & -0.1 & $70.2(0.47)$ & 0.5 & $68.5(0.49)$ & -0.1 & $68.4(0.50)$ & 2.8 \\
\hline
\end{tabular}

RMSE, coefficient of correlation ( $R^{2}$, values in brackets following RMSE) and bias were calculated on back-transformed values. RMSE, $R^{2}$ and bias were computed for an "all-sites" model as well as site-specific ones using calibration points at 1-ha and 0.25 -ha resolution, independently. On the other hand, LOSO RMSE, $R^{2}$ and bias corresponded to cases where models were calibrated without, and validated with, all the site-specific calibration points. Abbreviations: $\mathrm{H}_{50}$ median height of the canopy height model; TCH mean top-of-canopy height.

3) Stand-Scale AGB Modeling: Correlations between lidarderived and field-based AGB estimates were higher at 1-ha compared to 0.25-ha resolution (see Table III). Except on rare occasions, site-specific bias was expectedly lower than the one derived from the LOSO procedure. Results were more mixed concerning RMSE, and overall suggested suitable transferability of the "all-sites" model to predict AGB at the landscape scale across all sites. Some RMSE and bias values (both for site-specific and LOSO models) were unrealistically high. This was especially true for Mondah and Lopé, where the survey of distinct vegetation types over the same study site led to higher errors compared to other sites where vegetation was more homogenous. Despite contrasted results for site-specific models, we found $\mathrm{H}_{50}$ to be a better predictor of AGB compared to TCH in "all-sites" models at both resolutions. Therefore, each "all-sites" model with $\mathrm{H}_{50}$ as a sole predictor was selected for AGB modeling both at 1-ha and 0.25-ha resolutions (see Fig. 3).

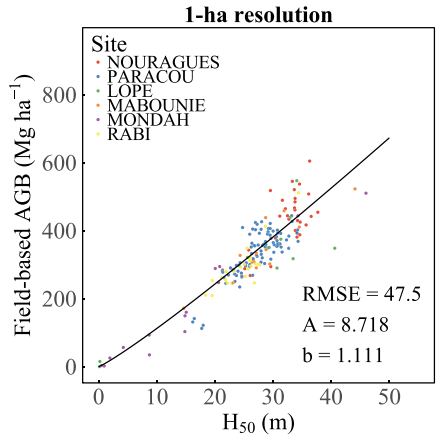

(a)

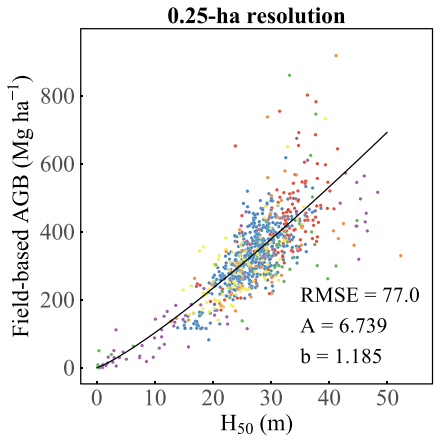

(b)
Fig. 3. Relationship between field-based AGB and lidar-derived median height of the CHM $\left(\mathrm{H}_{50}\right)$ over (a) 183 calibration points of one ha, and (b) 846 and 48 calibration points of 0.25 ha and 0.16 ha, respectively. Model form is $\widehat{\mathrm{AGB}}=A \times H_{50}{ }^{b}$, where the A coefficient is $\exp \left(a+\sigma^{2} / 2\right)$, built from the intercept of the log-log regression $a$ and the Baskerville correction factor $\exp \left(\sigma^{2} / 2\right)$. 


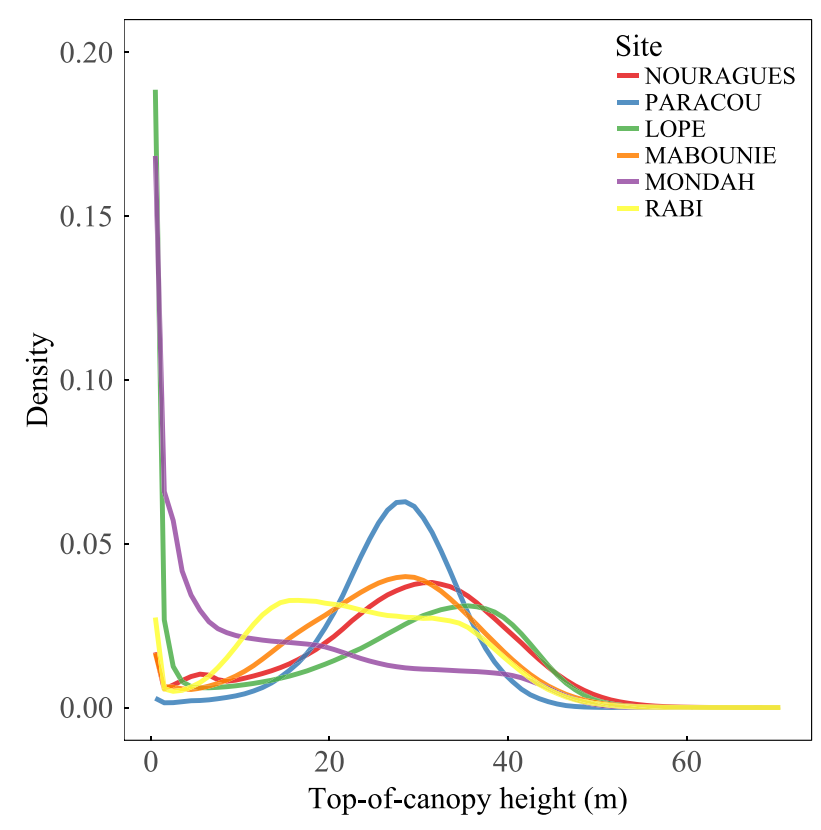

Fig. 4. Distribution of top-of-canopy height at 1-m resolution across study sites.

Relative RMSE of the "all-sites" models were $14.3 \%$ and $23.6 \%$ at 1-ha and 0.25 -ha resolutions, respectively.

\section{B. At the Landscape Scale}

1) Top-of-Canopy Height Distribution: Distribution of topof-canopy height varied across sites (see Fig. 4). Landscapes displaying a forest-savannah mosaic (Lopé) or large areas of human-disturbed vegetation (Mondah) had a different canopy height structure compared to closed-canopy forest landscapes.

The truncated bell-shaped distribution of the top-of-canopy height over Rabi (and to a lesser extent Mabounié) reflects the presence of bare soil, regenerating vegetation, and old-growth forest in the same landscape [47]. Top-of-canopy height was found to be spatially homogeneous in Paracou despite the experimental disturbance program conducted in the 80s (but note that out of the $10-15 \%$ of the landscape concerned by the program, some of this area served as control plots).

2) Aboveground Biomass: Patterns of AGB varied greatly across sites, with a number of explanatory causes, both natural and anthropic (see Fig. 5). For example, sharp AGB variations could be interpreted in terms of changes in vegetation type (savanna versus forest in Lopé, bamboo thickets or derived woodland versus closed-canopy forest in Nouragues or Mondah, respectively), the presence of geological features (granitic outcrop in the northern part of Nouragues) or artificial infrastructures such as roads (e.g., in Mabounié and Rabi). The density of high-biomass pixels ( $\mathrm{AGB}>600 \mathrm{Mg} \mathrm{ha}^{-1}$ at 0.25 -ha resolution) was highest at Lopé, followed by Mondah and Nouragues (see Fig. 8 in Appendix A).

\section{CONCLUdING REMARKS AND OUTLOOK}

\section{A. Spatial Mapping of $A G B$}

The model selected to infer AGB at the landscape scale was a simple power-law model that depended solely on $\mathrm{H}_{50}$ (rather

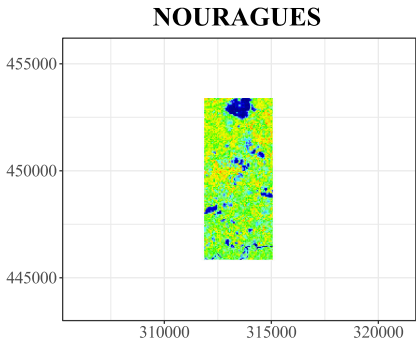

(a)

(c)

MONDAH

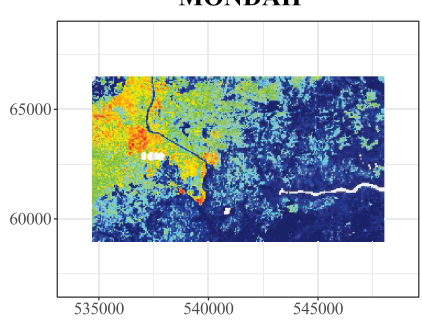

(e)

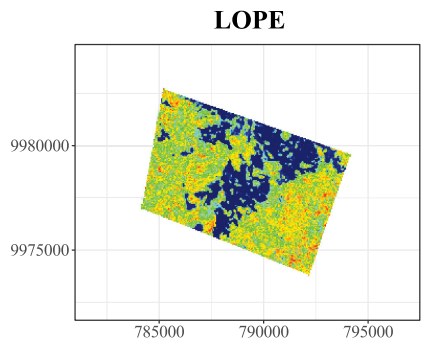

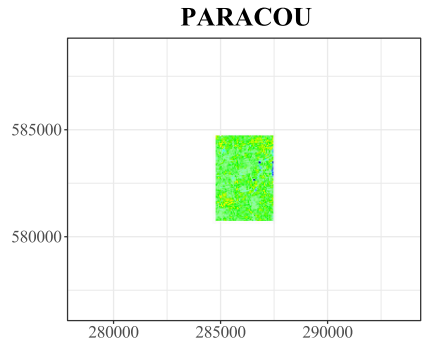

(b)

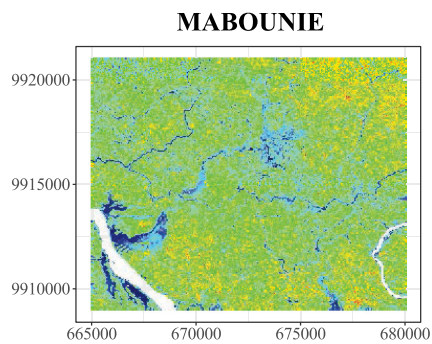

(d)

RABI

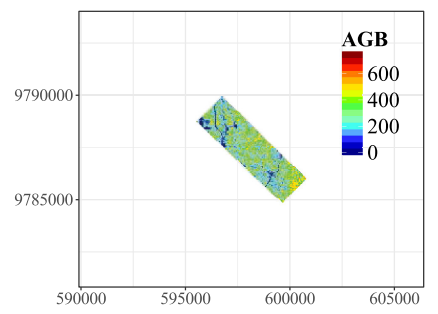

(f)
Fig. 5. Aboveground biomass (AGB, in $\mathrm{Mg} \mathrm{ha}^{-1}$ ) over each study site landscape. Maps of predicted AGB were originally built at 0.25 -ha resolution using a single "all-sites" relationship between AGB and median height of the CHM $\left(\mathrm{H}_{50}\right)$. All maps are displayed at the same scale. Maps of coarser resolution (obtained through pixel aggregation by a factor of 2 and 4 to reach 1-ha and 4-ha resolution, respectively; mean returned, no extension allowed) are available in the Dryad data repository that can be accessed from https://doi.org/10.5061/dryad.467hp97.

than TCH, though differences were small both in terms of RMSE and bias; see Table III), consistent with findings of [24]. Asner and Mascaro have argued that such a simple model would fail to capture regional variation in $\mathrm{BA}$ and $\mathrm{WD}$ across very different forest types [42], therefore limiting its predictive power at a global scale. Alternatively, they suggested the use of a generic or preferably, whenever field-based inputs are available, regionally calibrated models mirroring the structure of general tree-level allometric equations, i.e.,

$$
\widehat{\mathrm{AGB}}=\alpha \times \mathrm{TCH}^{\beta} \times \mathrm{BA}^{\gamma} \times \mathrm{WD}^{\delta}
$$

where $\mathrm{TCH}$ is the mean top-of-canopy height (m), BA is the stand basal area $\left(\mathrm{m}^{2} \mathrm{ha}^{-1}\right)$, and WD is the basal area-weighted wood density $\left(\mathrm{g} \mathrm{cm}^{-} 3\right)$. For such a model to be applied over the landscape, one approach is to regress BA and WD against TCH and to substitute these regressions back into (3) so that AGB prediction depends solely on TCH (which is mathematically equivalent to (2) as acknowledged in [42]). Such an approach was tested but did not lead to any prediction improvement (see Table V in Appendix C). Yet, apart from a few plots in savanna and human-disturbed vegetation, we have limited our analysis 
to tall closed-canopy forests in two regions and cannot therefore address Asner \& Mascaro's argument, as they compared much more contrasted forest types.

In the future, it would be interesting to explore further how to improve generic lidar-derived AGB models. Regressing BA against gap fraction at $20 \mathrm{~m}$ - the proportion of area not occupied by crown at $20 \mathrm{~m}$ aboveground-instead of $\mathrm{TCH}$ or $\mathrm{H}_{50}$, as advised in [43], is an option. However, here, it did not lead to any improvement of the model performances (results not shown, but raw data at 1 -ha and 0.25 -ha resolution are available in the Dryad data repository that can be accessed from https://doi.org/10.5061/dryad.467hp97). Alternatively, pointing out several structural problems in (3), Vincent et al. stressed that AGB can be more rigorously decomposed as the product of stem density, (a linear function of) quadratic diameter, and wood density [48]. While previous work showed that both stem density and quadratic diameter can be estimated from lidar [49], the authors emphasize the key role of forest stratification as a first step toward lidar-derived biomass mapping at the landscape scale [48]. Another prospect is that the wood density could be retrieved from space through biodiversity-related or physical metrics. Developments in airborne hyperspectral spectroscopy enable leaf trait mapping over extended areas [50], which could be related to wood density even though this is challenging [14], [51]. Passive and active microwave sensors are sensitive to vegetation water content (e.g., [52]) that has been shown to be related to the wood density [53].

\section{B. Prospects for Reducing Uncertainties}

Beyond uncertainties associated with the spatial mapping of AGB, errors inherent to stand biomass estimation (e.g., fieldbased tree measurement error and uncertainties associated with the allometric equation and sampling error) have already been emphasized [54]. An important aspect of this paper has been to account for the most important of these sources of error in the computation of credibility intervals associated to stand AGB [35], [55].

Other sources of uncertainties contributing to the overall error of the extrapolation model are often ignored:

1) field reporting errors (e.g., decimal place error, that can potentially lead to dramatic over- or under-estimation of AGB);

2) inaccurate or missing tree height measurements;

3) incorrect or missing tree identification;

4) time lag between ground and lidar data acquisition (that can represent up to $3 \%$ of the error on some stand parameters such as BA for a 6-8 year time lag in undisturbed forest [49] or more highly human-disturbed landscapes);

5) incorrect or missing within-plot tree coordinates;

6) inaccurate or missing plot coordinates; and

7) missing information about plot and subplot layout.

Accurate georeferencing of plots and individual trees is an essential step in the quality assessment of field-based datasets and is fundamental for an accurate match with remote sensing measurements [56]. Also, this would be important to support the recent development of individual tree crown approaches for stand-level biomass estimation [43], [57]. Although we coped with these errors to the best of our ability, such errors still impact the products. It will be key to minimize this kind of errors in upcoming field campaigns.

Lidar acquisition parameters are also known to influence the quality of AGB mapping. Biased tree height estimation due to low point density (e.g., when average point density drops below $4 \mathrm{~m}^{-2}$, which is the case at Lopé and Rabi; see Table I) can potentially lead to errors up to $125 \mathrm{Mg} \mathrm{ha}^{-1}$ in inferred AGB [58], especially when the landscape has a heterogeneous topography creating large errors in the DTM. As informative as average point density can be, it can potentially mask spatial heterogeneity in lidar acquisition across the landscape. Moving toward minimal common quality standards in terms of lidar acquisition parameters (e.g., in terms of point density and spatial homogeneity) should become a major operational objective.

\section{Recommendations}

Based on the above, we advocate for the following recommendations for future tropical forest field campaigns to generate data that would better serve the remote sensing community.

1) Strict compliance with the RAINFOR protocol [59] when establishing new plots or remeasuring existent ones. Using the protocol, crucial information is recorded at the plot level (e.g., plot orientation, plot coordinates, subplot layout), and tree level (e.g., XY relative coordinates, tag number, family and species name, diameter, point of measurement, measurement technique, height, bole form). As per the protocol instructions, lianas should also always be measured. Botanical identifications, from sample collection to identification to curation, play a critical role in the protocol. These activities are time consuming but are unavoidable in stem wood density assignation and subsequent AGB estimation. Though optional in the protocol, we stress that using a laser rangefinder to get stem XY relative coordinates should become a standard procedure for stem mapping.

2) Preferential use of data from permanent plots with multiple censuses. This is the key to ensure data quality as it is often the unique way to develop semiautomated quality checks (e.g., allowing to flag unrealistic increase/decrease in DBH from two successive DBH measurements).

3) Double entry of the data to cope with typographical errors (as suggested in [60]).

4) Optimization of both spatial and temporal matches between ground and lidar data acquisitions (e.g., through the use of a differential GPS in the field, and via budgeting of vegetation surveys concomitantly to the airborne campaign).

Ongoing initiatives aimed at building global databases of field-based forest biomass estimates should prioritize highquality data collected following clearly set standards. These initiatives include (but are not restricted to) the Forest Observation System (see http://forest-observation-system.net for details) and the "Biomass" focus area of the Land Product Validation subgroup of the Committee on Earth Observation Satellites (CEOS LPV; see https://lpvs.gsfc.nasa.gov for details). Only with high-quality ground data and a close connection with site primary investigators, will it be possible for spaceborne biomass missions to reach their full potential in reducing uncertainties regarding forest carbon stocks and fluxes. 


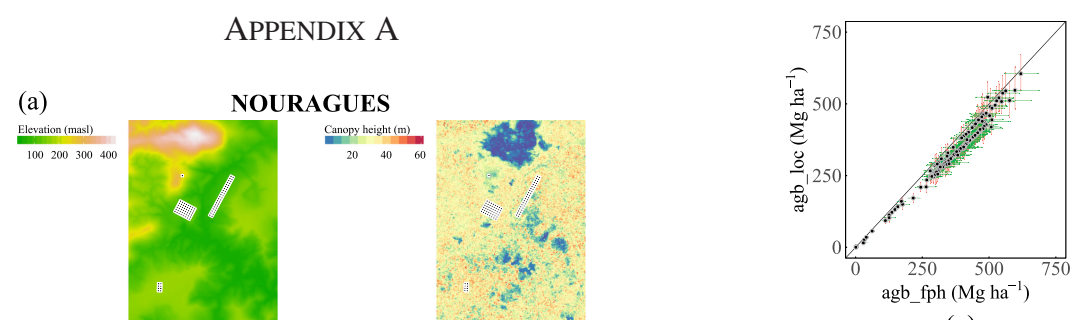

(a)

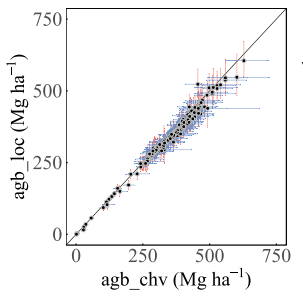

(b)

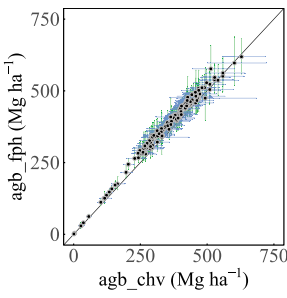

(c)

Fig. 7. Relationships between AGB estimates using three different allometries: "agb_fph" (where tree height is derived from regional H:D relationships), "agb_chv" (where tree height is implicitly taken into consideration through the use of bioclimatic predictor E), and "agb_loc" (where tree height is derived from local H:D relationships). Mean AGB estimates for 1-ha resolution calibration points $(n=183)$ are displayed along with their $95 \%$ credibility intervals. Note that most $95 \%$ credibility intervals cross the $1: 1$ line.

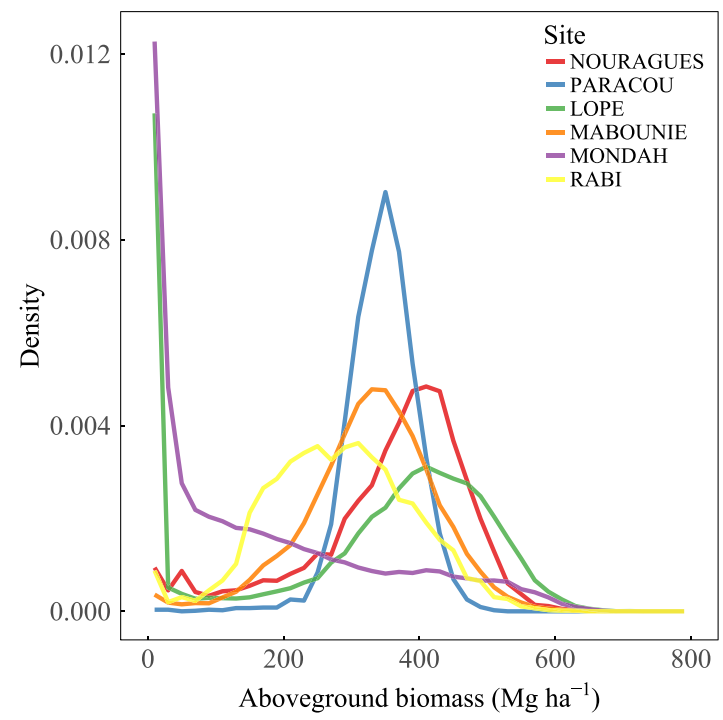

Fig. 8. Distribution of predicted aboveground biomass ( $\mathrm{AGB}$, in $\mathrm{Mg} \mathrm{ha}^{-1}$ ) at 0.25 -ha resolution over the different study sites.

(e)

MONDAH
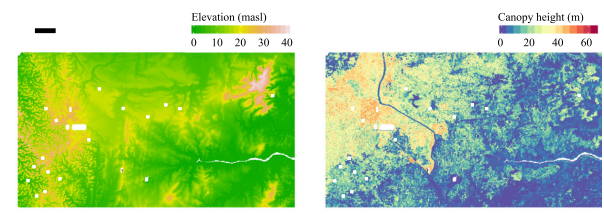

(f)

RABI
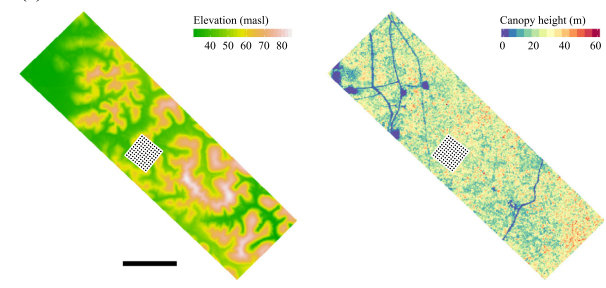

Fig. 6. Elevation (in meter above sea level; from the DTM) and canopy height (in meter; from the canopy height model) over each study site landscape. The location of permanent plots across the landscape is shown on each figure. Note that each square area represents a 0.25 -ha resolution calibration point (i.e., 50 $\mathrm{m} \times 50 \mathrm{~m}$ ) except at Mabounié where squares represent $100 \mathrm{~m} \times 100 \mathrm{~m}$ plots. For each study site, the black bar corresponds to $1 \mathrm{~km}$.

\section{APPENDIX B}

TABLE IV

\begin{tabular}{|c|c|c|c|c|}
\hline \multicolumn{5}{|c|}{$\begin{array}{c}\text { TABLE IV } \\
\text { COEFFICIENTS OF SITE-SPECIFIC AND REGIONAL HEIGH: } \\
\text { DIAMETER RELATIONSHIPS }\end{array}$} \\
\hline e/Region & $\mathrm{a}$ & $\mathrm{b}$ & $\mathrm{c}$ & RSE (m) \\
\hline JURAGUES & 55.795 & 34.698 & - & 3.967 \\
\hline RACOU & 46.479 & 27.674 & $\begin{array}{llll}- & & & \end{array}$ & 4.171 \\
\hline $\mathrm{PE}$ & 51.514 & 31.157 & - & 5.322 \\
\hline ABOUNIE & 59.675 & 46.187 & - & 6.573 \\
\hline ONDAH & 53.679 & 34.022 & $\begin{array}{llll}- & & & \end{array}$ & 7.431 \\
\hline $\mathrm{BI}$ & 51.342 & 35.954 & - & 4.495 \\
\hline ntral Africa & 50.453 & 0.0471 & 0.812 & 6.177 \\
\hline iana Shield & 42.845 & 0.0433 & 0.937 & 5.285 \\
\hline $\begin{array}{l}\text { specific } \mathrm{H}: \mathrm{D} \text { re } \\
\text { els of the form } \\
\text { relationships } \\
\text { developed in } \\
\hat{H}=a \times(1 \\
\text { relationships } \\
\text { lard error. }\end{array}$ & $\begin{array}{l}\text { vere used } \\
\text { he Feldpa } \\
\text { - exp }(-b \\
\text { ere used t }\end{array}$ & $\begin{array}{l}\text { t al. stuc } \\
\text { )). Tree } \\
\text { pute "ag }\end{array}$ & $\begin{array}{l}\text { s study u } \\
\text { height d } \\
\text { c." Regio } \\
\text { ] using } \\
\text { ht derive } \\
\text {." Abbre }\end{array}$ & $\begin{array}{l}\text { chaelis-Me } \\
\text { from these } \\
\text { D relations } \\
1 \text { models o } \\
\text { those regi } \\
\text { s: RSE resi }\end{array}$ \\
\hline
\end{tabular}

Several equations were used to estimate tree and palm AGB at the stem level. On the one hand, "agb_loc" and "agb_fph" estimates were obtained using the allometric (4) 
in Chave et al. [40]:

$$
\widehat{\mathrm{AGB}}_{\text {tree }}=0.0673 \times\left(\rho D^{2} H\right)^{0.976}
$$

where $\rho$ is the wood density $\left(\mathrm{g} \mathrm{cm}^{-3}\right), D$ is the diameter $(\mathrm{cm})$, and $H$ is the total height $(\mathrm{m})$ derived either from a local or regional H:D relationship, respectively. On the other hand, "agb_chv" was obtained using the modified version of (7) in Chave et al. (see [35] for details):

$$
\begin{aligned}
\widehat{\mathrm{AGB}}_{\text {tree }}= & \exp [-2.024-0.896 \times E+0.920 \times \ln (\rho) \\
& \left.+2.795 \times \ln (D)-0.0461 \times(\ln (D))^{2}\right]
\end{aligned}
$$

where $\rho$ is the wood density $\left(\mathrm{g} \mathrm{cm}^{-3}\right), D$ is the diameter $(\mathrm{cm})$, and $E$ is a local bioclimatic composite variable computed as follows:

$$
E=(0.178 \times \mathrm{TS}-0.938 \times \mathrm{CWD}-6.61 \times P S) \times 10^{-3}
$$

where TS is the temperature seasonality as defined in the Worldclim dataset (bioclimatic variable 4; see http://www. worldclim.org/bioclim), CWD is the climatic water deficit $\left(\mathrm{mm} \mathrm{yr}^{-1}\right)$, and PS is the precipitation seasonality as defined in the Worldclim dataset (bioclimatic variable 15). Palm AGB was estimated using the following equation developed for Amazon palms [39]:

$$
\widehat{\mathrm{AGB}}_{\text {palm }}=\exp \left[0.588^{2} / 2-3.3488+2.7483 \times \ln (D)\right] \times 10^{-3} .
$$

\begin{tabular}{|c|c|c|c|c|c|}
\hline & & $\mathrm{TCH}$ & & $\mathrm{H}_{50}$ & \\
\hline Resolution & Model & $\begin{array}{l}\text { RMSE } \\
\left(\mathrm{Mg} \mathrm{ha}^{-1}\right)\end{array}$ & $\begin{array}{l}\text { bias } \\
(\%)\end{array}$ & $\begin{array}{l}\text { RMSE } \\
\left(\mathrm{Mg} \mathrm{ha}^{-1}\right)\end{array}$ & $\begin{array}{l}\text { bias } \\
(\%)\end{array}$ \\
\hline \multirow[t]{2}{*}{$1 \mathrm{ha}$} & $\widehat{\mathrm{AGB}}=A \times H_{50}^{b}$ & $\begin{array}{r}51.7 \\
(0.79)\end{array}$ & 1.7 & $\begin{array}{r}47.5 \\
(0.81)\end{array}$ & 2.1 \\
\hline & $\begin{array}{l}\widehat{\mathrm{AGB}}=\alpha \times \mathrm{TCH}^{\beta} \\
\times \mathrm{BA}^{\gamma} \times \mathrm{WD}^{\delta}\end{array}$ & $\begin{array}{r}48.5 \\
(0.80) \\
\end{array}$ & -0.5 & $\begin{array}{r}48.2 \\
(0.80) \\
\end{array}$ & -1.3 \\
\hline \multirow[t]{2}{*}{0.25 ha } & $\widehat{\mathrm{AGB}}=A \times H_{50}{ }^{b}$ & $\begin{array}{r}82.0 \\
(0.60) \\
\end{array}$ & 2.1 & $\begin{array}{r}77.0 \\
(0.62) \\
\end{array}$ & 1.9 \\
\hline & $\begin{array}{l}\widehat{\mathrm{AGB}}=\alpha \times \mathrm{TCH}^{\beta} \\
\times \mathrm{BA}^{\gamma} \times \mathrm{WD}^{\delta}\end{array}$ & $\begin{array}{r}77.8 \\
(0.61) \\
\end{array}$ & -0.8 & $\begin{array}{r}77.4 \\
(0.61) \\
\end{array}$ & -1.4 \\
\hline
\end{tabular}

\section{APPENDIX C}

TABLE V

COMPARISON OF Model PERFormances For StAND-SCAlE AGB PREDICTION

Two models were compared: the model used in this study ( $\widehat{\mathrm{AGB}}=A \times H_{50}{ }^{b}$ ) and the regionally calibrated one proposed by Asner and Mascaro ( $\widehat{\mathrm{AGB}}=\alpha \times$ $\mathrm{TCH}^{\beta} \times \mathrm{BA}^{\gamma} \times \mathrm{WD}^{\delta}$; see [42]). Ordinary least squares regressions on log-log transformed data were performed using 183 and 894 calibration points at 1-ha and 0.25 -ha resolution, respectively. RMSE, coefficient of correlation $\left(R^{2}\right.$, values in brackets following RMSE), and bias were calculated on back-transformed values. Abbreviations: $\mathrm{H}_{50}$ median height of the canopy height model; $\mathrm{TCH}$ mean top-ofcanopy height.

\section{ACKNOWLEDGMENT}

The authors are deeply grateful to field, the many field staff in French Guiana and Gabon who collected data, and without whom this paper would not have been possible. They particularly want to thank C. Ditougou, A. Dibambou, P. Dimbonda, E. Dimoto (Lopé campaign), P. Ploton, V. Droissart, and Y.
Issembe (Mabounié) for their help and expertise. They warmly thank Dr. T. Stévart from Missouri Botanical Garden for his help on vernacular name elucidation. They would also thank (Lopé campaigns), D. Nguema, L. Tchignoumba, G. Moussavou, E. Moumoulossi, P. Biessemou, W. Mbading-Mbading, and G. Villa (Rabi campaigns) the Gabon Parks Agency (ANPN), the Gabon Space Agency (AGEOS), and National Center for Scientific and Technical Research (CENAREST) for facilitating fieldwork in the country. Field campaigns at Mabounié were performed in collaboration with the Missouri Botanical Garden (Tariq Stévart) and Golder Associates. The Rabi 25-ha is a collaborative project of CENAREST, the Center for Conservation and Sustainability (CCS) of the Smithsonian Conservation Biology Institute and the Center for Tropical Forest ScienceForest Global Earth Observatories (CTFS-ForestGEO) of the Smithsonian Tropical Research Institute.

\section{REFERENCES}

[1] S. L. Lewis, "Tropical forests and the changing earth system," Philos. Trans. Roy. Soc. B, Biol. Sci., vol. 361, pp. 195-210, 2006.

[2] J. W. F. Slik et al., "An estimate of the number of tropical tree species," in Proc. Nat. Acad. Sci., Jun. 2015, pp. 7472-7477.

[3] Millennium Ecosystem Assessment, "Forest and Woodland Systems," in Ecosystems and Human Well-Being: Current State and Trends, vol. 1, R. M. Hassan, R. Scholes, and N. Ash, Eds. Washington, DC, USA: Island Press, 2005, pp. 585-621.

[4] N. Labrière, B. Locatelli, Y. Laumonier, V. Freycon, and M. Bernoux, "Soil erosion in the humid tropics: A systematic quantitative review," Agri. Ecosyst. Environ., vol. 203, pp. 127-139, May 2015.

[5] R. T. Corlett, "The impacts of droughts in tropical forests," Trends Plant Sci., vol. 21, pp. 584-593, Jul. 2016.

[6] Y. D. Pan et al., "A large and persistent carbon sink in the world's forests," Science, vol. 333, pp. 988-993, Aug. 2011.

[7] S. Pacala and R. Socolow, "Stabilization wedges: Solving the climate problem for the next 50 years with current technologies," Science, vol. 305, pp. 968-972, Aug. 2004.

[8] K. Hoshizaki et al., "Temporal and spatial variation of forest biomass in relation to stand dynamics in a mature, lowland tropical rainforest, Malaysia," Ecological Res., vol. 19, pp. 357-363, May 2004.

[9] J. Chave, R. Condit, S. Lao, J. P. Caspersen, R. B. Foster, and S. P. Hubbell, "Spatial and temporal variation of biomass in a tropical forest: Results from a large census plot in Panama," J. Ecol., vol. 91, pp. 240-252, Apr. 2003.

[10] S. S. Saatchi et al., "Benchmark map of forest carbon stocks in tropical regions across three continents," Proc. Nat. Acad. Sci. USA, vol. 108, pp. 9899-9904, Jun. 2011.

[11] A. Baccini et al., "Estimated carbon dioxide emissions from tropical deforestation improved by carbon-density maps," Nature Climate Change, vol. 2, pp. 182-185, Mar. 2012.

[12] V. Avitabile et al., "An integrated pan-tropical biomass map using multiple reference datasets," Global Change Biol., vol. 22, pp. 1406-1420, Apr. 2016.

[13] E. T. Mitchard et al., "Uncertainty in the spatial distribution of tropical forest biomass: A comparison of pan-tropical maps," Carbon Balance Manage., vol. 8, pp. 1-13, Oct. 2013.

[14] E. T. Mitchard et al., "Markedly divergent estimates of Amazon forest carbon density from ground plots and satellites," Global Ecol. Biogeography, vol. 23, pp. 935-946, Aug. 2014.

[15] A. E. Lugo and S. Brown, "Tropical forests as sinks of atmospheric carbon," Forest Ecol. Manage., vol. 54, pp. 239-255, Nov. 1992.

[16] S. L. Lewis et al., "Increasing carbon storage in intact African tropical forests," Nature, vol. 457, pp. 1003-1006, Feb. 2009.

[17] O. L. Phillips et al., "Drought sensitivity of the Amazon rainforest," Science, vol. 323, pp. 1344-1347, 2009.

[18] B. Hérault et al., "Modeling decay rates of dead wood in a neotropical forest," Oecologia, vol. 164, pp. 243-251, Sep. 2010.

[19] T. Le Toan et al., "The BIOMASS mission: Mapping global forest biomass to better understand the terrestrial carbon cycle," Remote Sens. Environ. vol. 115, pp. 2850-2860, 2011. 
[20] ESA, "Report for mission selection: Biomass, ESA SP-1324/1 (3 volume series)," Noordwijk, The Netherlands: European Space Agency, 2012.

[21] A. Moreira et al., "Tandem-L: A highly innovative bistatic SAR mission for global observation of dynamic processes on the earth's surface," IEEE Geosci. Remote Sens. Mag., vol. 3, no. 2, pp. 8-23, Jun. 2015.

[22] P. C. Dubois-Fernandez et al., "The TropiSAR airborne campaign in French Guiana: Objectives, description, and observed temporal behavior of the backscatter signal," IEEE Trans. Geosci. Remote Sens., vol. 50, no. 8, pp. 3228-3241, Aug. 2012

[23] I. Hajnsek et al., "3-D SAR imaging of African forests: Results from the AfriSAR campaign at P- and L-Band," presented at the Proc. 11th European Conf. Synthetic Aperture Radar, 2016, pp. 1-4.

[24] M. Réjou-Méchain et al., "Using repeated small-footprint LiDAR acquisitions to infer spatial and temporal variations of a high-biomass Neotropical forest," Remote Sens. Environ., vol. 169, pp. 93-101, Nov. 2015.

[25] O. Poncy et al., "The permanent field research station 'Les Nouragues' in the tropical rainforest of French Guiana: Current projects and preliminary results on tree diversity, structure, and dynamics," in Forest Biodiversity in North, Central and South America and the Carbbean: Research and Monitoring, F. Dallmeier and J. Comiskey, Eds., Lancs, U.K.: UNESCO, Paris and Parthenon Publishing Group, 1998, pp. 385-410.

[26] S. Gourlet-Fleury, J.-M. Guehl, and O. Laroussinie, Ecology and Management of a Neotropical Rainforest: Lessons Drawn From Paracou, a Long-Term Experimental Research Site in French Guiana. Paris, France: Elsevier, 2004.

[27] L. Blanc et al., "Dynamics of aboveground carbon stocks in a selectively logged tropical forest," Ecological Appl., vol. 19, no. 6, pp. 1397-1404, 2009.

[28] T. Chiti et al., "Impact of woody encroachment on soil organic carbon storage in the Lopé National Park, Gabon," Biotropica, vol. 49, pp. 9-12, Jan. 2017

[29] L. J. White, "Forest-savanna dynamics and the origins of Marantaceae forest in central Gabon," in African Rain Forest Ecology and Conservation: An Interdisciplinary Perspective, W. Weber, L. J. White, A. Vedder, and L. Naughton-Treves, Eds. New Haven, CT, USA: Yale Univ. Press, 2001, pp. $165-182$.

[30] M. Nziengui et al., "Suivi par télédétection de la dynamique des milieux savanicoles et forestiers gabonais: Exemples de la forêt classée de la Mondah et du parc national de la Lopé," Photo-Interprétation, vol. 44, pp. 14-23, 2008.

[31] O. Lachenaud, T. Stévart, D. Ikabanga, E. C. N. Ndjabounda, and G. Walters, "Les forêts littorales de la région de Libreville (Gabon) et leur importance pour la conservation: description d'un nouveau Psychotria (Rubiaceae) endémique," Plant Ecol. Evol., vol. 146, pp. 68-74, 2013.

[32] M. C. Hansen et al., "High-resolution global maps of 21st-century forest cover change," Science, vol. 342, pp. 850-853, Nov. 2013.

[33] G. Walters et al., "Peri-urban conservation in the Mondah forest of Libreville, Gabon: Red List assessments of endemic plant species, and avoiding protected area downsizing," Oryx, vol. 50, pp. 419-430, Jul. 2016.

[34] H. R. Memiaghe, J. A. Lutz, L. Korte, A. Alonso, and D. Kenfack, "Ecological importance of small-diameter trees to the structure, diversity and biomass of a tropical evergreen forest at rabi, Gabon," PLoS One, vol. 11, May 2016, Art. no. e0154988.

[35] M. Réjou-Méchain, A. Tanguy, C. Piponiot, J. Chave, and B. Hérault, "BIOMASS: An R package for estimating aboveground biomass and its uncertainty in tropical forests," Methods Ecol. Evol., vol. 8, pp. 11631167, Mar. 2017.

[36] Q. Molto, B. Hérault, J. J. Boreux, M. Daullet, A. Rousteau, and V. Rossi, "Predicting tree heights for biomass estimates in tropical forests \&ndash; a test from French Guiana," Biogeosciences, vol. 11, pp. 3121-3130, 2014.

[37] J. Chave, D. Coomes, S. Jansen, S. L. Lewis, N. G. Swenson, and A. E. Zanne, "Towards a worldwide wood economics spectrum," Ecol. Lett., vol. 12, pp. 351-366, Apr. 2009.

[38] A. E. Zanne et al., "Data from: Chave J, Coomes D, Jansen S, Lewis SL, Swenson NG, Zanne AE. Towards a worldwide wood economics spectrum. Ecol. Lett. 2009; 12: 351-366," Dryad Data Repository. [Online]. Available: http://dx.doi.org/10.1111/j.1461-0248.2009.01285.x, 202009.
[39] R. C. Goodman et al., "Amazon palm biomass and allometry," Forest Ecol. Manage., vol. 310, pp. 994-1004, 2013.

[40] J. Chave et al., "Improved allometric models to estimate the aboveground biomass of tropical trees," Global Change Biol., vol. 20, pp. 3177-3190, 2014.

[41] T. R. Feldpausch et al., "Tree height integrated into pantropical forest biomass estimates," Biogeosciences, vol. 9, pp. 3381-3403, 2012.

[42] G. P. Asner and J. Mascaro, "Mapping tropical forest carbon: Calibrating plot estimates to a simple LiDAR metric," Remote Sens. Environ., vol. 140, pp. 614-624, 2014.

[43] D. A. Coomes et al., "Area-based vs tree-centric approaches to mapping forest carbon in Southeast Asian forests from airborne laser scanning data," Remote Sens. Environ., vol. 194, pp. 77-88, 2017.

[44] G. L. Baskerville, "Use of logarithmic regression in the estimation of plant biomass,” Can. J. Forest Res., vol. 2, pp. 49-53, 1972.

[45] R Core Team, "R: A language and environment for statistical computing," R Foundation for Statistical Computing, Vienna, Austria. [Online]. Available: http://www.R-project.org/, 2017.

[46] F. E. Putz and K. H. Redford, "The importance of defining 'Forest' Tropical forest degradation, deforestation, long-term phase shifts, and further transitions," Biotropica, vol. 42, no. 1, pp. 10-20, 2010.

[47] P. Kennel, M. Tramon, N. Barbier, and G. Vincent, "Canopy height model characteristics derived from airbone laser scanning and its effectiveness in discriminating various tropical moist forest types," Int. J. Remote Sens., vol. 34, pp. 8917-8935, 2013.

[48] G. Vincent, D. Sabatier, and E. Rutishauser, "Revisiting a universal airborne light detection and ranging approach for tropical forest carbon mapping: Scaling-up from tree to stand to landscape," Oecologia, vol. 175, pp. 439-443, 2014.

[49] G. Vincent et al., "Accuracy of small footprint airborne LiDAR in its predictions of tropical moist forest stand structure," Remote Sens. Environ., vol. 125, pp. 23-33, 2012.

[50] G. P. Asner et al., "Airborne laser-guided imaging spectroscopy to map forest trait diversity and guide conservation," Science, vol. 355, pp. 385$389,2017$.

[51] C. Baraloto et al., "Decoupled leaf and stem economics in rain forest trees," Ecol. Lett., vol. 13, pp. 1338-1347, 2010.

[52] T. Emmerik et al., "Water stress detection in the Amazon using radar," Geophys. Res. Lett., vol. 44, pp. 6841-6849, 2017.

[53] D. P. Dias and R. A. Marenco, "Tree growth, wood and bark water content of 28 Amazonian tree species in response to variations in rainfall and wood density," iForest-Biogeosci. Forestry, vol. 9, pp. 445-451, 2016.

[54] Q. Molto, V. Rossi, and L. Blanc, "Error propagation in biomass estimation in tropical forests," Methods Ecol. Evol., vol. 4, pp. 175-183, 2013.

[55] J. Chave, R. Condit, S. Aguilar, A. Hernandez, S. Lao, and R. Perez, "Error propagation and scaling for tropical forest biomass estimates," Philos. Trans. Roy. Soc. London B, Biol. Sci., vol. 359, pp. 409-420, 2004.

[56] M. Réjou-Méchain et al., "Local spatial structure of forest biomass and its consequences for remote sensing of carbon stocks," Biogeosciences, vol. 11, pp. 6827-6840, 2014.

[57] A. Ferraz, S. Saatchi, C. Mallet, and V. Meyer, "Lidar detection of individual tree size in tropical forests," Remote Sens. Environ., vol. 183, pp. 318-333, 2016.

[58] V. Leitold, M. Keller, D. C. Morton, B. D. Cook, and Y. E. Shimabukuro, "Airborne lidar-based estimates of tropical forest structure in complex terrain: Opportunities and trade-offs for REDD+," Carbon Balance Manage., vol. 10, pp. 1-12, Feb. 2015.

[59] O. L. Phillips, T. R. Baker, R. J. W. Brienen, and T. R. Feldpausch, "RAINFOR: Field Manual for Plot Establishment and Remeasurement," 2016. [Online]. Available: http://www.geog.leeds.ac.uk/projects/rainfor/.

[60] R. Condit, Tropical Forest Census Plots: Methods and Results From Barro Colorado Island, Panama and a Comparison With Other Plots. New York, NY, USA: Springer, 1998.

Authors' photographs and biographies not available at the time of publication. 